\title{
Nudges y decisiones inconscientes: sesgo de statu quo y políticas públicas en Colombia
}

DANIEL A. MonRoy C.*

Archivo recibido: 21 de marzo de 2016

Archivo aprobado: 14 de diciembre de 2016

Doi: http://10.12804/revistas.urosario.edu.co/desafios/a.4725

Para citar este artículo: Monroy C., Daniel A. (2017). Nudges y decisiones inconscientes: sesgo de statu quo y políticas públicas en Colombia. Desafios, 29(1), 211-247. Doi: http:/ /10.12804/ revistas.urosario.edu.co/desafios/a.4725

\section{Resumen}

El artículo presenta una sintesis de una anomalía cognitiva denominada comúnmente como "sesgo de statu quo" y muestra cómo esta puede influir en la toma de decisiones individuales y por tanto, en la efectividad de las políticas públicas en algunos contextos relevantes, entre ellos: (i) los malos hábitos alimenticios de las personas; y (ii) el problema de la calidad del aborro para pensiones de jubilación. Además, el articulo sugiere algunas estrategias (nudges) acerca de cómo la prevalencia del "sesgo de statu quo" podría servir a los diseñadores de políticas como una herramienta para el mejor diseño y la efectividad de las políticas en los mismos contextos mencionados. El articulo finaliza con una breve reflexión acerca de la ética y el uso de nudges por parte de los mencionados diseñadores.

Palabras clave: Behavioral economics, sesgo de statu quo, paternalismo libertario y políticas públicas.

\footnotetext{
* Investigador, Universidad Externado de Colombia, Departamento de Derecho Económico, Bogotá, Colombia. Correo electrónico: daniel.monroy@uexternado.edu.co. ORCID: http://orcid.org/0000-0003-0519-7992
} 


\title{
Nudges and Unaware Choices: Statu Quo Bias and Public Policies in Colombia
}

\begin{abstract}
The article presents, first, a synthesis of the cognitive anomaly called "statu quo bias" and shows how this bias could infuence individual decision-making and therefore also the effectiveness of public policies in some relevant contexts, among them: (i) people's bad eating habits; and (ii) the quality of savings for retirement. Second, the article suggests some strategies (nudges) about how the prevalence of "statu quo bias" could be used by policymakers as a tool to design or to improve the effectiveness of public policies in each of those contexts. The article ends with a brief consideration of the ethics and the use of nudges by policymakers.
\end{abstract}

Keywords: Behavioral economics, statu quo bias, libertarian paternalism; policymaking.

\section{Nudges e decisões inconscientes: viés de statu quo e políticas públicas na Colômbia}

\section{Resumo}

$O$ artigo apresenta uma sintese de uma anomalia cognitiva denominada comumente como "viés de statu quo" e mostra como esta pode influir na tomada de decisões individuais e portanto, na efetividade das politicas públicas em alguns contextos relevantes, entre eles: (i) os maus hábitos alimentares das pessoas; e (ii) o problema da qualidade da poupança para pensões de aposentadoria. Além disso, o artigo sugere algumas estratégias (nudges) acerca de como a prevalência do "viés de statu quo" poderia servir aos desenhadores de politicas como uma ferramenta para o melhor desenho e a efetividade das políticas nos mesmos contextos mencionados. $O$ artigo finaliza com uma breve reflexão acerca da ética e o uso de nudges por parte dos desenhadores mencionados.

Palavras-chave: Economia comportamental, viés de statu quo, paternalismo libertário e políticas públicas. 


\section{Introducción: Behavioral economics vs. Economía convencional}

Conforme la corriente dominante de la economía, el individuo actúa como un agente racional en el sentido en que a la decisión le antecede un análisis costo-beneficio respecto de cada uno de los cursos de acción disponibles, y dentro de estos selecciona aquel que maximice su función de utilidad; también se asume que sin importar el tipo de decisión dentro o fuera del mercado, esta se dirige a satisfacer el interés propio del decisor; además, se dice que los individuos se comportan consistentemente según un conjunto de preferencias exógenas y estables en el tiempo. ${ }^{1}$ Con todo, la economía convencional defiende con vehemencia que las personas (a quienes se designan como bomo economicus) actúan conforme los axiomas de lo que se denomina como Teoría de la Acción Racional (TAR).

Por supuesto, la utilidad instrumental de la TAR se sostiene en los innumerables casos en los cuales los comportamientos individuales se adecuan $-y$ por tanto pueden pronosticarse ex ante- conforme dicho modelo comportamental. Empero, entre otras objeciones, se dice que este enfoque suele restarle importancia a la influencia que juegan otros factores, como el entorno social o ciertas variables psicológicas en la formación de las preferencias y en la toma de decisiones. En este orden, más que homo economicus, enfoques comportamentales alternativos contemplan al individuo como un ser que suele tomar decisiones impulsado además por sus emociones y con una alta dependencia del contexto -no solo el entorno social- en el cual actúa.

Si bien resulta trivial defender la idea de que existen perspectivas comportamentales críticas de la TAR, lo cierto es que entre estas la defendida por el Behavioral Economics $(B E)$ es la que ha recibido la mayor atención (incluso fuera de la academia) en las últimas décadas, ha obtenido una progresiva cantidad de simpatizantes, y por lo mismo,

\footnotetext{
Sobre la noción de "exogeneidad de la preferencia" cfr. Frank (2005, p. 223) y Monroy (2015, p. 10).
} 
ha sido el blanco de críticas incisivas por parte de los economistas más convencionales. ${ }^{2}$

En lo referente a la noción de BE, vale decir que esta perspectiva es “... [el resultado de] la combinación entre la psicología y la economía con el fin de investigar lo que sucede en los mercados en los cuales alguno de los agentes presenta una limitación o complicación [cognitiva]" (Mullainathan \& Thaler, p. 2).

Sobre la noción transcrita, y tal como se ha defendido previamente, ${ }^{3}$ se observa que esta (i) está dada en términos de complementación, es decir, más que suplementar la TAR, lo que propone el BE es una integración entre teorías psicológicas y económicas, a fin de explicar de forma más precisa ciertos comportamientos que los agentes despliegan en el mercado, y por otro lado, (ii) evidencia que el rasgo distintivo del BE gira en torno a la necesidad de sintetizar un sesgo o una "anomalía" cognitiva en la toma de decisión individual.

Por su parte, las anomalías cognitivas (en adelante anomalías) son un término acuñado inicialmente por el economista cognitivo Richard Thaler, quien entre 1987 y 1991 publicó una serie de artículos en el Journal of Economic Perspectives, a cuyos títulos les antepuso precisamente el término anomalías. ${ }^{4} \mathrm{El}$ objetivo común de estos trabajos consistía en evidenciar comportamientos individuales que se desviaban anómala,

\footnotetext{
2 Por ejemplo, el célebre Gary Becker (2012) objetaba el BE pues, en su opinión, este se concentra en los comportamientos que despliegan algunos individuos, pero sin tener en cuenta los efectos agregados; también sostenía que la capacidad predictiva del BE es inferior a la del enfoque convencional; y que algunos de los que consideran como "nuevos" hallazgos del $B E$, en realidad ya estaban incorporados de tiempo atrás en la teoría económica convencional.

3 cfr. Monroy (2014, p. 60).

4 Han sido más de veinte los artículos sobre anomalías escritos por Thaler -la mayoría en coautoría con otros behavioralistas-, entre los que cabe destacar los relacionados con los comportamientos cooperativos vs. los comportamientos tipo gorrón (freerider) en el contexto de la provisión de bienes públicos (Dawes \& Thaler, 1988); cooperación y juego del ultimátum (Thaler R. , 1988); decisión intertemporal (Loewenstein \& Thaler, 1989); ahorros, violación de la fungibilidad del dinero, autocontrol y el fenómeno de la contabilidad mental (Thaler R. , 1990); el fenómeno de la reversión de la preferencia (Tversky \& Thaler, 1990); la teoría prospectiva, el efecto dotación y el Teorema de Coase (Kahneman, Knetsch, \&
} 
pero sistemática y predeciblemente de las hipótesis comportamentales deducibles de la TAR, ofreciéndose entonces explicaciones cognitivas alternativas que no podían explicarse -al menos completamente- a partir del paradigma comportamental de la economía convencional.

Si bien la identificación y síntesis de tales anomalías se considera como el principal aporte del BE, simultáneamente es el detonante del más agitado debate académico entre los behavioralistas y los economistas más tradicionales. Así, por un lado, las abundantes pruebas experimentales que soportan la existencia de tales anomalías han permitido avanzar en la síntesis de los contextos fácticos en los cuales es altamente probable que se presenten aquellas, así como también han permitido predecir la trayectoria de los comportamientos individuales, incluso en términos agregados. Esta particularidad ha permitido que el $\mathrm{BE}$ se presente como un enfoque más congruente con la realidad en comparación con lo que sucede con la TAR, pero, simultáneamente, tal fortaleza se ve aminorada en la medida que no es plausible hablar de una única anomalía comportamental, ${ }^{5}$ e incluso, existen importantes dificultades y desacuerdos entre académicos acerca de cómo agrupar tales anomalías en un número relativamente restringido de marcos teóricos. ${ }^{6}$ Esto último implica que los supuestos comportamentales identificados por el BE -pese a su eventual mayor congruencia con la realidad-son escasamente generalizables

Thaler, 1990); la teoría prospectiva, el efecto dotación y el sesgo de statu quo (Kahneman, Knetsch, \& Thaler, 1991), entre otros.

5 A título ilustrativo, en una importante colección de artículos editada por Camerer, Loewenstein \& Rabin (2004) que pretendía dar cuenta de los avances más relevantes del BE hasta la fecha, se verifica la síntesis de al menos 35 anomalías del comportamiento, algunas denominadas bajo la categoría de sesgos (sesgo por el interés personal, sesgo de confirmación, sesgo optimista); otras bajo los títulos de heurísticas (disponibilidad, representatividad, anclaje); otras denominadas como aversiones (aversión a las pérdidas, a la ambigüedad); otras, los llamados efectos (efecto dotación, efecto marco), más otras tantas como el descuento hiperbólico o la contabilidad mental, etc.

6 Por ejemplo, Wright \& Ginsburg (2012) engloban las diferentes anomalías en dos grandes categorías: (ii) Efectos contextuales y (ii) errores de auto-control. Por su parte, Jolls, Sunstein, \& Thaler (1998) agrupan las diferentes anomalías en torno a tres limitaciones (bounds) de la conducta humana: (i) racionalidad limitada, (ii) fuerza de voluntad limitada e (iii) interés propio limitado. A su turno, Ho, Lim, \& Camerer (2006) efectúan tal agrupación en torno a las categorías de: (i) estructuración de preferencias e (ii) interacción entre individuos. 
en comparación con aquellos derivados de la TAR (Fudenberg, 2006; Camerer \& Loewenstein, 2004).

Para nuestros efectos (el contexto de las políticas públicas), lo anterior supone que existe siempre un límite práctico a cualquier aproximación que pretenda partir del enfoque del BE para explicar y anticipar los comportamientos que en general despliegan los individuos en la realidad. En específico, no resulta factible agotar en un único escrito la manera como desde el BE se pueden pronosticar los comportamientos individuales de cara a las políticas públicas, ni la manera como puede servir a los diseñadores de políticas en el mejor diseño de aquellas. De hecho, una nota común de los trabajos relacionados con la aplicación del BE es que estos suelen aludir a unas muy pocas anomalías del comportamiento y simultáneamente evidencian algunos contextos restringidos en los cuales las anomalías pueden tener alguna injerencia, ya sea desde una perspectiva positiva o normativa.

En este orden de ideas, el presente escrito está sujeto a dos limitaciones metodológicas comunes a cualquier aproximación del BE en el contexto de las políticas públicas: (i) Por un lado, que la escogencia de la (o las) anomalías a partir de las cuales se efectúa la aproximación al contexto en concreto, es siempre una cuestión arbitraria; (ii) por otro lado y sin perjuicio de la anomalía que se escoja, esta puede entenderse en una doble connotación: una negativa, en el sentido en que, por definición, la anomalía supone siempre una desviación de las hipótesis deducibles de la TAR, y por tanto, un eventual obstáculo para la efectividad de las políticas públicas, pero también una connotación positiva, en el sentido que si tal desviación es sistemática y predecible, entonces el diseñador de la política pública puede valerse de la misma anomalía como una herramienta para mejorar el diseño de la propia política.

Con estas precisiones en mente, el trabajo se dirige a presentar una perspectiva descriptiva y otra normativa del enfoque del BE en el contexto de las políticas públicas. En concreto, nuestro objetivo se dirige a sintetizar algunos contextos restringidos pero relevantes en materia de las políticas públicas, la prevalencia de la anomalía cognitiva denominada 
"sesgo de statu quo" en la toma de decisiones a través de un análisis descriptivo, y a partir de este, sintetizar de qué manera la prevalencia de este sesgo podría servir a los encargados de las políticas públicas como una herramienta para el mejor diseño y la efectividad de las mismas en algunos contextos también restringidos (análisis normativo).

Para efectos de satisfacer el objetivo señalado, el presente escrito se divide en tres secciones. En la primera sección delimitamos el contenido de nuestra "caja de herramientas". Concretamente, en el subnumeral 1.1., se describe someramente la denominada Teoría Prospectiva, y en el contexto de esta se sintetiza la anomalía denominada "sesgo de statu quo". En el subnumeral 1.2. se defiende la noción del paternalismo suave y el concepto del "nudge", como herramienta a partir de la cual-según los behavioralistas - el diseñador de la política pública podría diseñar o mejorar la efectividad de las políticas públicas en ciertos contextos. En la segunda sección presentamos dos casos de aplicación de la "caja de herramientas". Específicamente, en la primera aplicación se parte del sesgo de statu quo, y desde una perspectiva descriptiva se pretende establecer una relación entre esta anomalía y la persistencia de algunos (malos) hábitos alimenticios presentes incluso entre la población colombiana. En este contexto, se sugieren algunos otros nudges que permitirían al diseñador de la política mejorar la efectividad de las medidas dirigidas a corregir dichos hábitos. La segunda aplicación se relaciona con el problema de la calidad del ahorro para pensiones de jubilación. Ahí se argumenta que aunque las medidas de corte paternalista "duro" pueden ser necesarias, también es cierto que una dosis adicional de paternalismo "suave" puede ser también útil. Finalmente, en la tercera sección el artículo presenta un subrepticio marco de reflexión (y discusión) acerca del trasfondo ético y moral que supone el paternalismo "suave" y la utilización de nudges como alternativa de política pública. 


\section{Caja de herramientas: Sesgo de statu quo y "paternalismo suave"}

\subsection{Teoría Prospectiva y sesgo de statu quo}

En uno de los artículos seminales del enfoque del BE, Kahneman \& Tversky (1979) formularon la denominada Teoría Prospectiva, según la cual, en escenarios de incertidumbre, a los individuos no les resulta tan relevante las magnitudes de cada posible resultado, como si lo es el punto referencia a partir del cual se toma la decisión. Contrario a lo defendido convencionalmente por la economía, esta teoría sostiene que en escenarios de incertidumbre, el individuo suele tomar en cuenta su situación subjetiva y previa a la decisión, es decir, su referencia inicial. Concretamente, se dice que la formación de las preferencias y la evaluación de las opciones de decisión disponibles está más determinada por las comparaciones que se hacen a partir de un estado de cosas referente (statu quo) que por los resultados absolutos (valores objetivos) que cada opción representa. Desde la perspectiva del $B E$, a este supuesto comportamental se le suele denominar como "dependencia de la referencia" (Amir \& Lobel, 2008, p. 2112).

Anudado a lo anterior, la Teoría Prospectiva también sostiene que los individuos suelen modificar sensiblemente su comportamiento a partir del mismo punto de referencia y dependiendo de si la decisión señala un resultado favorable o desfavorable. En breve, se dice que los individuos tienden a modificar sus actitudes respecto del riesgo, otorgando un mayor valor "subjetivo" a las pérdidas que a las ganancias, aunque las magnitudes "objetivas" de aquellas y estas sean las mismas (Kahneman \& Tversky, 1979, p. 279) . Así, en un escenario de pérdidas, los individuos tienden a optar por las opciones más arriesgadas, mientras que, en el terreno de las ganancias, las decisiones tienden a agruparse en torno a las opciones más seguras. En otras palabras, se dice que existe una disparidad entre la mayor aversión a las pérdidas a partir de un punto de referencia y un menor deseo por las ganancias de magnitud objetiva equivalente. A este otro supuesto comportamental se le denomina como "aversión a las pérdidas". (Camerer \& Loewenstein, 2004, p. 4). 
Para efectos ilustrativos, la figura 1 muestra la función de valor que se deriva de la Teoría Prospectiva. Conforme esta, y según lo anotado en los párrafos precedentes, esta función posee las siguientes dos propiedades: (i) se define en términos de ganancias y pérdidas, a partir de un punto de referencia (dependencia de la referencia) y no en términos de utilidad total; y (ii) la pendiente de la función en el escenario de las perdidas es mayor que la de las ganancias para iguales valores objetivos (aversión a las pérdidas) (Tversky \& Kahneman, 1979, 1991; Kahneman, 2011). ${ }^{7}$

Figura 1. Función de valor en la Teoría Prospectiva

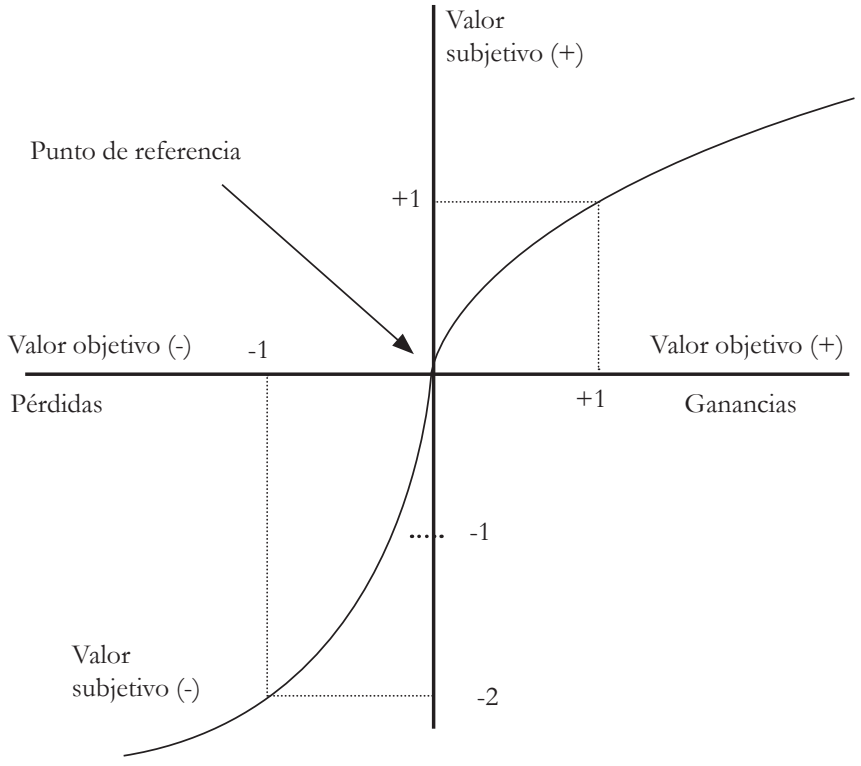

Fuente: elaboración propia a partir de Tversky \& Kahneman, 1979.

Ahora, de la Teoría Prospectiva se derivan una serie de anomalías cognitivas, tales como el "efecto dotación" y el sesgo de statu quo; este último se suele definir como la tendencia anómala de los individuos a

Existe una tercera propiedad de la función y es que esta es cóncava en el terreno de las ganancias y convexa en el dominio de las perdidas (disminución de la sensibilidad).

8 A título ilustrativo, en un reciente artículo (Monroy, 2016), presentamos un desarrollo y aplicación del "efecto dotación" en materia de regulación y políticas públicas medioambientales. 
favorecer la "inercia" en la toma de decisión, es decir, a mantener el estado de cosas referente (el statu quo) porque abandonarlo se percibe como una perdida, y abstenerse de tomar decisiones que modifiquen dicho statu quo, esto último aun cuando la alternativa pueda representar un mejor resultado en términos objetivos. ${ }^{9}$

Así, desde una perspectiva descriptiva, el reconocimiento de anomalías tales como el sesgo de statu quo puede incidir en el pronóstico de los comportamientos individuales y, por ende, en la efectividad de las políticas públicas, pero por el otro lado, y desde una perspectiva prescriptiva, el reconocimiento de tal anomalía pueden suministrar una base para mejorar el diseño de la política en algunos contextos. Sobre este último punto en concreto, de tiempo atrás el BE ha defendido la noción de "paternalismo suave" como principio de aplicación al diseño de políticas públicas en aquellos contextos en los que los individuos se comportan anómalamente.

\subsection{Paternalismo suave: Nudges}

Por definición, el "paternalismo" implica que en ciertas situaciones algunos individuos saben mejor que otros qué decisión mejorará la situación de estos últimos, es decir, el paternalismo asume que existen personas que no están en una buena posición para elegir bien para "sí mismos", en comparación con la posición en la que se encuentran “otros"(Calabresi \& Melamed, 2011), y por tanto, que es legítimo que en ocasiones "otros" implementen medidas autoritarias y restrictivas, tendientes a dirigir a la persona a lo que es más conveniente para sus propios intereses, necesidades o bienestar. ${ }^{10}$

\footnotetext{
$9 \quad$ Este sesgo es inicialmente sintetizado por Samuelson y Zeckhauser (1998), quienes lo definen básicamente como "(...) [la tendencia a] no hacer nada o a mantener la decisión actual o anterior(...)". El mismo sesgo es definido por Kahneman, Knetsch, \& Thaler (1991) como "(...)una fuerte tendencia a permanecer en el statu quo, porque las desventajas de dejarlo se ponderan más que las ventajas".

10 Véase la definición de paternalismo propuesta en el trabajo de Dworkin (1990) quien la entiende en sentido lato como "(...) la interferencia en la libertad de una persona justificada por razones que se refieren exclusivamente al bienestar, al bien, a la felicidad, a las necesidades, a los intereses o a los valores de la persona coaccionada" (p. 148).
} 
Empero, la crítica recurrente a las medidas paternalistas es que estas tienden a coaccionar, prohibir y restringir la autonomía individual, incluso cuando la decisión que se restringe afecta exclusivamente al mismo individuo. Por supuesto, existe el caso excepcional de la decisión individual de esclavizarse, en el que una medida paternalista parece incontrovertible, ${ }^{11}$ pero, en general tales tipos de restricciones en la toma de decisión resultan prima facie cuestionables, en especial por quienes defienden concepciones filosóficas "libertarias". ${ }^{12}$ Así, en casos como el consumo de sustancias adictivas, el uso del cinturón de seguridad o los hábitos alimenticios, mientras los paternalistas "duros" tenderán a apoyar medidas prohibitivas o restrictivas de la decisión, en el mismo caso, los libertarios tenderán a defender con vehemencia la autonomía individual, y que a través de ella los mismos individuos autorregulen su comportamiento.

Como se puede apreciar, el paternalismo y la filosofía libertaria se conciben como posiciones inicialmente antagónicas entre sí. Sin embargo, es en este contexto en el que "paternalismo suave" se presenta como una tercera vía, una alternativa de conciliación entre estos dos extremos. En concreto, el "paternalismo suave" y las políticas que de este se derivan, se consideran en todo caso "paternalistas", en la medida que "[...] intentan influir en las decisiones [individuales] de manera que quienes deciden salgan beneficiados a juicio de ellos mismos [...] [es decir, se pretende orientar a las personas] en direcciones que mejorarán sus vidas" (Thaler \& Sunstein, 2009, pp. 19-20). Simultáneamente, el "paternalismo

11 En el famoso ensayo de John S. Mill titulado Sobre la libertad, se defiende la prohibición de esclavizarse como la única excepción de aplicación de una medida paternalista, según el autor porque "(...) al venderse como esclavo, un hombre abdica a su libertad. Destruye (...) la razón por la cual le era permitido disponer libremente de su persona" (1980, p. 114); dicho de otra manera, para Mill, la única libertad de la que carece el individuo es la de poder renunciar a su propia libertad, y por tanto, se justifica que el Estado aplique esta única excepción paternalista, en el sentido de prohibir que el individuo pueda tomar "libremente" la decisión de renunciar a su libertad.

12 Aunque existen diversas posiciones filosóficas consideradas libertarias, estás suelen estar construidas conceptualmente a partir de las objeciones al paternalismo, por ejemplo, la definición de libertad individual en Kant, está construida como una crítica a la arbitrariedad utilitarista, el despotismo de la benevolencia paternalista y el paternalismo autoritario (Demenchonok, 2009). 
suave", se considera en todo caso "suave", en oposición al paternalismo "duro", por cuanto no pretende proscribir ni coaccionar ningún curso de acción individual en específico; por el contrario, supone que " $[. .$. las personas deben tener la libertad de desvincularse de las medidas [paternalistas] preestablecidas si es que así deciden hacerlo." (Sunstein \& Thaler, 2003, p. 1161).

Por muchas razones, los "behavioralistas" suelen alinearse y defender el "paternalismo suave". En efecto, si los individuos se comportan en ciertos contextos de manera "anómala", entonces parece legítimo que el gobierno aplique al menos una dosis "suave" de paternalismo a fin de guiar a los individuos hacía mejores decisiones y, de esta manera, mitigar los efectos negativos de tales anomalías. Sin embargo, el hecho de que algunos individuos suelan comportarse anómalamente es un argumento insuficiente para implementar políticas restrictivas de las decisiones (paternalismo duro), pues de prohibirse u ordenarse un curso de acción en específico, se imponen costos injustificados a aquellos otros individuos que toman las mismas decisiones, pero por razones racionales. De esta última idea se infiere que las medidas de corte "paternalista suave" resultan relativamente inobjetables por la filosofía libertaria, en contraste con las objeciones que esta filosofía presenta cuando se opta por medidas paternalistas más "duras" (Conly, 2013).

Ahora, en la literatura del BE, Thaler y Sunstein (2009) y (2012) han acuñado el término nudge (pequeño empujón) para referirse a las medidas, incluso gubernamentales, que se alinean con el "paternalismo suave". Según los autores, un nudge consiste en estructurar el contexto, el marco, las opciones, y la denominada "arquitectura de la decisión", con el fin de "empujar" a las personas hacia una dirección que es ex ante predecible, que mejore su propio bienestar, pero sin proscribir ni ordenar autoritariamente ninguna opción en particular y siendo siempre posible que la persona se desvincule o evite fácilmente la medida si es que así lo desea. ${ }^{13}$ Ya en el contexto específico de las

\footnotetext{
13 Para una definición más extensa del “nudge” cfr. Balz, Sunstein, \& Thaler (2013) y Sunstein \& Thaler (2003b).
} 
políticas públicas, un nudge puede definirse como "Una política dirigida a modificar un comportamiento [anómalo] pero sin modificar el conjunto de opciones de decisión. Tal política no prohíbe, penaliza o premia ninguna opción en particular. En su lugar, guía a las personas hacia una elección en particular cambiando la opción por defecto, la descripción o el punto de referencia" (World Bank, 2015, p. 36).

Para finalizar esta parte del trabajo, y conforme a lo anticipado en la parte introductoria, lo que hemos pretendido es sintetizar el contenido de la "caja de herramientas" que utilizaremos en la sección de aplicaciones. En concreto, en la sección que prosigue (re)abordaremos el sesgo de statu quo y a partir de este, sintetizaremos - desde una perspectiva descriptiva- algunos casos relevantes en materia de políticas públicas, en los cuales la presencia de esta anomalía puede constituir un eventual obstáculo para la efectividad de las mismas. Seguidamente, y desde una perspectiva normativa, utilizaremos el enfoque indicado en la subsección 1.2. (paternalismo suave), a fin de recomendar algunos nudges de los cuales podrían valerse el gobierno para mejorar la efectividad de las políticas públicas.

\section{Aplicaciones: Utilizando la caja de herramientas}

\section{1. (Malos) hábitos alimenticios en Colombia y sesgo de statu quo}

Tal como se indicó en la sección precedente, el sesgo de statu quo puede llevar a los individuos a repetir o mantener irreflexivamente una misma decisión por ninguna otra razón diferente a que dicha opción es la predeterminada, es decir, el "estado de cosas inicial", y esto aun cuando esta opción pueda modificarse, y la alternativa pueda representar incluso un mejor resultado para el individuo (Downs, Loewenstein, \& Wisdom, 2009). En este orden de ideas, se ha afirmado, por ejemplo, que ciertas normas jurídicas efectivamente predeterminan opciones de decisión, que como tal fijan un statu quo (Camerer, Issacharoff, Loewenstein, O’Donoghue, \& Rabin, 2003). Por lo mismo, podría sostenerse que tanto los legisladores como los 
responsables de diseñar las políticas podrían valerse de determinado diseño de las normas, para lograr resultados socialmente deseables.

Empero, no solamente las normas jurídicas establecen statu quo; también, las tradiciones, las costumbres heredadas entre un grupo de personas, los hábitos familiares, o de los habitantes de una misma región, y en general, lo que otros hacen o deciden, pueden generar un estado de cosas referente (statu quo), y de esta manera, incidir sesgadamente en las decisiones individuales (Huh, Vosgerau, \& Morewedge, 2014), y por lo mismo, pueden ayudarnos a explicar por qué y cómo corregir ciertos comportamientos socialmente negativos.

En efecto, el contexto social en el que el individuo actúa influye drásticamente en su decisión (World Bank, 2015); así, si bien a veces la utilidad individual de "seguir la tradición" puede derivarse de la mayor identidad o el mayor nivel de aceptación que le genera al individuo el replicar el hábito grupal, en otras ocasiones los individuos simplemente repiten por inercia tales tradiciones ( $v g r$. las costumbres familiares), es decir, replican un comportamiento inconscientemente por el simple hecho de que "es lo que hacen los demás". ${ }^{14}$ Según algunos autores, tales hábitos y la dinámica de cómo estos se replican por los individuos pueden entenderse como situaciones de "statu quo", frente a las cuales el grupo y sus miembros suelen resistir el cambio, aun cuando los beneficios individuales de replicar tal comportamiento resulten bien cuestionables (Korobkin \& Ulen, 2010).

Ahora, un caso peculiar en el cual parece tener especial relevancia la lógica de hacer "lo que otros hacen" es el relacionado con los hábitos alimenticios. $\mathrm{Al}$ respecto, considérese en el caso colombiano la manera

\footnotetext{
14 Este comportamiento de "hacer lo que hacen los demás" - de la manera descrita- a menudo se asocia con el comportamiento manada (herd behavior), el cual se define como una forma en que" $[. .$.$] los pensamientos y comportamientos de los individuos se alinean$ con los de un grupo (manada) a través de la interacción local y sin ninguna coordinación centralizada" (Raafat, Chater, \& Frith, 2009, p. 420), y puede tener una incidencia particular incluso en el contexto de los -malos- hábitos alimentarios; así, por ejemplo, se ha encontrado que las personas con amigos obesos son más propensos a ser también obesos (Luoto \& Carman, 2014).
} 
como ciertas tradiciones y costumbres alimenticias pueden llegar a afectar la prevalencia del sobrepeso entre la población.

Al respecto, la última Encuesta Nacional de la Situación Nutricional - ENSIN (2010) encontró una incidencia del sobrepeso de más del $50 \%$ entre la población encuestada. Especialmente se detectó que en todos los niveles del SISBEN (niveles socioeconómicos más bajos) la prevalencia del exceso de peso supera el 45\%, lo cual sugiere que el nivel de ingreso está escasamente relacionado con los niveles de obesidad entre la población.

Una de las causas de la incidencia del sobrepeso es que entre la población colombiana existe una alta incidencia en el consumo de grasas saturadas y alimentos de alto contenido calórico (Ministerio de Protección Social, 2011), así como también un bajo consumo de frutas y verduras tanto a nivel rural como urbano, y esto último, sin que existan evidencias de que el nivel de ingreso sea un determinante del mayor o menor consumo de estos alimentos (Ministerio de Salud y Protección Social, 2013). ${ }^{15}$ Estos hallazgos son considerados incluso "anormales" por la misma ENSIN, en la medida que la condición tropical de Colombia supone una gran variedad, altos niveles de producción y precios relativamente bajos de frutas y verduras, por lo que no es claro el porqué del bajo nivel de consumo de este tipo de alimentos (Ministerio de Salud y Protección Social, 2013).

15 El estudio realizado por el Ministerio de Salud (2013) caracteriza el consumo de frutas y verduras, y encontró que el nivel de consumo diario per capita de frutas y verduras en el país es en promedio de $224.65 \mathrm{gr} /$ día, siendo la mediana de consumo de verduras de 45,75 gr/día y el de frutas de $88 \mathrm{gr} /$ día; estos niveles de consumo están muy por debajo de lo recomendado (entre 400 y $500 \mathrm{gr} /$ día). Por otro lado, no se pudo establecer una relación clara entre niveles SISBEN y el mayor o menor consumo de estos alimentos. Desagregando los resultados del estudio se encuentra que, en lo que corresponde a las verduras, los departamentos que presentan un mayor consumo per capita son los santanderes, Bogotá, Huila y Meta (63 gr/día), y los de menor consumo son Vaupés, Chocó y Amazonas (26 gr/día); no se observan diferencias significativas en el consumo de verduras al comparar área rural y urbana. Para el caso de las frutas, el estudio sí encontró que su consumo aumenta ligeramente a mayor clasificación del SISBEN; a nivel de departamentos, San Andrés, Sucre, Bolívar, Quindío, Risaralda y Bogotá presentan los niveles de consumo mas altos (114 gr/día), y Guaviare, Vichada y Amazonas, los más bajos. (57 gr/día): adicionalmente, se observa un mayor consumo en el área rural sobre el área urbana. 
En este orden, una de las metas del Plan Nacional de Seguridad Alimentaria y Nutricional 2012-2019 consiste en reducir la prevalencia del exceso de peso a niveles entre el 44\% y 30\% (Presidencia de la República, 2013); sin embargo, según el mismo gobierno, uno de los obstáculos para cumplir esta meta se relaciona con el hecho de que tales comportamientos no saludables suelen estar determinados particularmente por factores culturales, tradiciones, hábitos familiares e incluso las relaciones de poder al interior de las familias (statu quo) (Ministerio de Salud y Protección Social, 2013).

Lo anterior sugiere que una política pública cuya finalidad sea mitigar los problemas actuales de sobrepeso en la población debe contemplar el hecho de que estos pueden estar determinados -parcialmente-por el sesgo de statu quo y la lógica de "hacer lo que otros hacen", sesgos que puede determinar, por ejemplo, que al interior de las familias o en las escuelas, los individuos repliquen por inercia e inconscientemente, comportamientos alimentarios no saludables tales como los señalados. En este caso, consideramos que los diseñadores de las políticas pueden valerse de algunos nudges con el fin de mejorar la efectividad de estas e incentivar comportamientos más saludables.

\subsubsection{Nudges y corrección de (malos) hábitos alimenticios}

Son múltiples los nudges que pueden diseñarse para modificar los malos hábitos alimenticios entre la población. Así, por ejemplo, los behavioralistas han encontrado que en presencia del mismo tipo de alimentos, cuando los recipientes en los que se disponen tales alimentos son de mayor tamaño, las personas tienden a consumir más del mismo alimento (Wansink, 1996), ello no solo cuando parecen ser poco saludables, sino cuando no tienen buen sabor (Wansink \& Kim, 2005). Esta idea sugiere que introduciendo cambios en los tamaños de los empaques de los alimentos, es posible disuadir comportamientos alimenticios poco saludables (alimentos grasosos o azucarados en empaques más pequeños) y simultáneamente incentivar el consumo de otros alimentos más saludables (alimentos a base de fruta en empaques más grandes). 
De otra parte, la mayor efectividad de las políticas en salud depende parcialmente de que estas se concentren en los grupos demográficos que están en mayor riesgo; en el caso de la alimentación, estos grupos parecen ser los niños y las personas más jóvenes (Wansink \& Cheney, 2006).

Para el caso de Colombia, y en lo relativo a dichos grupos de mayor riesgo, la ENSIN (2010) indica que existen problemas de sobrepeso incluso entre niños y jóvenes. Concretamente, la encuesta revela que existe una prevalencia de sobrepeso del $17.5 \%$ entre menores de los diferentes niveles del SISBEN, y se dice que en el área urbana tal prevalencia es de casi el 20\%. Aunque esta situación puede deberse a los hábitos alimenticios que se replican al interior de las familias, también se asocia con factores tales como: (i) la alimentación que se suministra a los menores en las escuelas y (ii) el mayor acceso y gusto de los menores por alimentos poco saludables, como las comidas rápidas y ciertos alimentos empacados (Sunstein, 2011).

Para coadyuvar a la reducción de la obesidad entre la población infantil, y en lo que respecta a los cambios en los tamaños de los empaques, los responsables de formular las políticas podrían propiciar la generación de algunos nudges, ello generando alianzas entre el sector público y los productores de alimentos, para que estos últimos reduzcan los tamaños de los empaques de alimentos poco saludables de especial gusto por los niños y jóvenes. Un antecedente al respecto existe en EE.UU., en donde, en el marco del programa gubernamental "Let's Move!", dirigido a controlar la obesidad entre jóvenes y niños, empresas productoras de alimentos como Kraft Foods, General Mills, CocaCola y Kellogg se comprometieron a reducir el contenido calórico de varios de sus productos, y también a reducir el tamaño de las porciones de algunos alimentos empacados (Sunstein, 2011).

Pero quizá es en el contexto de las escuelas en donde el abanico de nudges tendientes a corregir malos hábitos alimenticios es más amplio 
y particularmente más efectivo ${ }^{16}$. $\mathrm{Al}$ respecto, el Center for Behavioral Economics in Child Nutrition Programs (B.E.N. Center) de la Universidad de Cornell, ha sugerido la implementación de algunos nudges de muy bajo costo, aplicables a nivel de los comedores de las escuelas. Según un estudio empírico del B.E.N. Center adelantado en diferentes comedores de escuelas en EE.UU., se demostró que la sola modificación de los nombres corrientes de los vegetales por otros particularmente llamativos, incrementa considerablemente el consumo de este tipo de alimentos por parte de los niños. En concreto, el estudio demostró que, por ejemplo, al cambiar el nombre de las "zanahorias" por el de "Zanahorias visión de rayos X", estudiantes de entre 8 y 11 años incrementaron el consumo de zanahorias en un 66\% (Wansink, Just, Payne \& Klinger, 2012).

\subsection{Ahorro para pensiones de jubilación en Colombia y sesgo de statu quo}

Un segundo caso en el que los behavioralistas han dado importantes avances es el de las políticas dirigidas a incentivar el ahorro entre las personas, y dentro de estas, las relacionadas específicamente con el ahorro dirigido a obtener una pensión de vejez. Vale decir que, a nivel local, lo relacionado con la regulación y la política dirigida a garantizar el acceso y el autofinanciamiento de las pensiones es un problema particularmente crítico. ${ }^{17}$

$\mathrm{Al}$ respecto, lo primero es recordar que a partir de 1993 coexisten en Colombia dos sistemas pensionales, a saber: (i) el denominado sistema de prima media, y (ii) el sistema de ahorro individual. Una de las características diferenciadoras de este último es que el valor de la mesada pensional de jubilación depende exclusivamente del

\footnotetext{
16 Véase Thapaa \& Lyford (2014) en donde se hace una revisión sistemática de la literatura relativa a la aplicación de herramientas del BE en el contexto de los comedores escolares.

17 Los problemas de las pensiones asociados a la insuficiencia de las mesadas, la baja cobertura y los problemas de financiación son relativamente comunes en toda Latinoamérica y se encuentran bastante bien diagnosticados en la literatura, para efectos puede consultarse Lora \& Pagés (2000); Ayala \& Acosta (2002); Mesa-Lago (2004); López \& Lasso (2012); Banco Interamericano de Desarrollo (2015), entre otros.
} 
monto del capital y de los rendimientos financieros acumulados en la cuenta individual del ahorrador, por tanto, entre mayor haya sido el nivel de ahorro y mayor el tiempo en que el capital haya generado rendimientos, mayor será el valor de la pensión a la que se accede.

Empero, más allá de los problemas asociados a los bajos niveles de cotización en el país por razones asociadas con el reducido nivel de ingresos, los altos niveles de informalidad en el empleo y la brecha en materia de ingreso entre trabajadores urbanos y rurales, ${ }^{18}$ también se ha diagnosticado que las personas de más altos ingresos, con mayores niveles de educación o que acceden y mantienen un empleo formal durante varios años, no destinan la suficiente cantidad de dinero al ahorro como para garantizarse incluso a sí mismos una mesada pensional suficiente y, de hecho, exhiben una alarmante despreocupación por su futuro financiero.

En efecto, un estudio realizado por López y Lasso (2012), encuentra que en Colombia solo entre el 30\% y 40\% de los jóvenes profesionales hacen algún tipo ahorro (voluntario u obligatorio) para su pensión. También se encontró que el 32\% de quienes cuentan con educación superior dice no hacer nada para garantizarse a sí mismo un ingreso durante su vejez. Sobre este mismo punto, otra encuesta del Banco Mundial (2013) muestra que si bien el 88\% de los colombianos consideran que anticipar los gastos de la vejez es algo de lo que hay que preocuparse, solo el 25\% de los menores de 60 años efectúa aportes para obtener una pensión de jubilación, y el 65\% de los mayores de 60 años aceptan no haber efectuado las previsiones suficientes o no haber planificado "nada" para su propia vejez. De hecho, al cuestionarse a

18 Según la última Encuesta Longitudinal de Protección Social para Colombia realizada por el DANE (2014) se encontró que solamente el 37\% de la población mayor de 15 años realiza algún tipo de cotización a pensiones. Entre asalariados, la encuesta reveló que en áreas urbanas el 61\% son cotizantes y en áreas rurales se reduce al 35\%. En lo que corresponde a trabajadores independientes, la situación es particularmente crítica, pues en áreas urbanas solamente el 10\% realiza cotizaciones, y en áreas rurales este porcentaje se reduce al 3\%. Al contrastar las cifras por regiones, la encuesta no encuentra diferencias significativas, sin embargo, se destaca que, mientras en Bogotá, el 72\% de los asalariados y el 22\% de los independientes son cotizantes, en la región oriental, 55\% de los asalariados y el 9\% de los independientes realizan cotizaciones. 
los encuestados sobre su actitud respecto de su futuro financiero, el $55 \%$ de ellos estuvo de acuerdo o muy de acuerdo con la afirmación de que el en la vejez "Dios proveerá".

La contradicción en el comportamiento de los trabajadores colombianos que se induce de lo recién indicado es evidente: aunque la mayoría de ellos (incluso los mejor preparados y con mayores ingresos) son conscientes de que ahorrar para su propia pensión de jubilación es muy importante, en general se comportan como si tuviesen una intención contraria, o al menos, que tienen muchas dificultades para apegarse, cumplir en el corto plazo con los planes de ahorro que ellos mismos consideran que maximizan sus intereses en el largo plazo. Los behavioralistas analizan esta disparidad entre la "intención" de la persona en el largo plazo y el "comportamiento actual" bajo el concepto de la "fuerza de voluntad limitada" (bounded willpower) para con ello referirse a la incapacidad de las personas para mantenerse y cumplir expost los planes que se fijaron ex ante. ${ }^{19}$

\subsubsection{Nudges para mejorar la calidad del ahorro para jubilación}

Ahora, las personas suelen ser conscientes de sus problemas de debilidad de la voluntad, y en consecuencia, suelen aceptar e incluso autoimponerse restricciones $e x$ ante a fin de no contar ex post con la opción -la tentación- de incumplir sus planes en el futuro. Es por ello que, por ejemplo, quienes pretenden dejar el tabaco suelen compran cigarrillos al menudeo, y no por paquetes (Monroy, 2012), o que quienes desean cumplir un plan de ahorro, en ocasiones lo hacen inscribiéndose voluntariamente en planes informales -pero muy restrictivos-, como las "cadenas de ahorro" o ROSCAs (Rotating Savings \& Credit Associations), los cuales son sistemas de ahorro particularmente populares en países en desarrollo y entre las comunidades de más bajos ingresos (Gugerty, 2007; Collins, Morduch, Rutherford \& Ruthven, 2009).

\footnotetext{
19 Véase Kooreman \& Henriëtte (2010) quienes presentan el problema de la "debilidad de la voluntad" en el contexto del ahorro, definiéndola como la diferencia entre las "preferencias normativas" (qué tanto debería ahorrar) y las "preferencias reveladas" (qué tanto estoy ahorrando actualmente).
} 
Por supuesto, si la mala planificación financiera y el problema de la debilidad de la voluntad explica parcialmente los bajos niveles de ahorro, pareciera entonces legítimo forzar a las personas a que se inscriban y a que permanezcan inscritos en planes de ahorro a largo plazo que incrementen obligatoriamente el monto de sus cotizaciones y prohibirles que puedan disponer de sus ahorros antes del momento de la jubilación. Si bien este tipo de medidas de corte paternalista "duro" han generado impactos positivos en materia pensional, en este aparte del trabajo nos concentraremos en sintetizar un nudge que, basado en el sesgo de statu quo, ha sido implementado en Colombia (sospechamos que de manera involuntaria) y que ciertamente ha modificado el comportamiento de las personas respecto de sus decisiones de ahorro para pensión.

$\mathrm{Al}$ respecto, como ya se ha sugerido, una de las expresiones del sesgo de statu quo se manifiesta en la tendencia generalizada de los individuos a no tomar decisiones activas, sino más bien a actuar tomando el "camino que ofrece menor resistencia", esto es, aceptando pasivamente las opciones por defecto, ya sea que estas opciones se encuentren predefinidas en un software (Kesan \& Shah, 2006), en un formulario (Ariely, 2008), en un contrato (Korobkin R. B., 1998) o en la regulación misma (Camerer, Issacharoff, Loewenstein, O’Donoghue, \& Rabin, 2003).

En el caso concreto del ahorro, existe una abundante literatura que señala que las opciones de inscripción "por defecto" de los trabajadores en planes de ahorro voluntario para la pensión eleva significativamente la propensión de los mismos trabajadores a inscribirse y a permanecer en dichos planes por incluso largos periodos de tiempo (Madrian \& Shea, 2001; Choi, Laibson, Madrian \& Metrick, 2002, 2004; BEshears, Choi, Laibson \& Madrian, 2009).

Así, para el caso de EE.UU. los trabajadores tienen la opción de inscribirse en planes voluntarios de jubilación 401(k), en los cuales autoriza a su empleador a que retenga parte del salario a pagar y en su lugar, dirija ese dinero hacia una cuenta de inversión a la cual solo puede accederse una vez aquel cumpla la edad de jubilación. El tra- 
bajador sin embargo es libre de decidir y modificar el porcentaje del salario que será consignado en su cuenta de jubilación, así como el nivel de riesgo al que expone su inversión, y además puede retirarse del plan cuando lo desee. Empero, la evidencia empírica demuestra que cuando la opción por defecto, es decir, el statu quo inicial, señala que el trabajador se encuentra inscrito en el plan, a menos que manifieste explícitamente su decisión de retirarse (sistema opt-out choice), ello eleva significativamente las tasas de ahorro en el corto y largo plazo, en comparación a cuando la opción "por defecto" es que el trabajador no está inscrito en el plan a menos que manifieste su decisión de inscribirse (sistema opt-in choice) (Madrian \& Shea, 2001). Concordante con el sesgo de statu quo, la evidencia también señala que los trabajadores tienden a aceptar pasivamente -a no modificar- el porcentaje del salario que la empresa predeterminadamente decide retener, así como tampoco suelen modificar el nivel de riesgo al que su inversión se expone "por defecto".

Esta tendencia a actuar por inercia, a no modificar las opciones "por defecto" en materia de ahorro individual para la jubilación, posee un importante reflejo en el contexto de la regulación local. En efecto, en Colombia a partir de 2009 los trabajadores cotizantes en el sistema de ahorro individual cuentan con la opción de escoger entre tres portafolios de inversión diferenciados, según el nivel de riesgo al que está expuesta la inversión (riesgo conservador, riesgo moderado o alto riesgo). La idea de este sistema de "multifondos" es que el cotizante elija "libremente" la conformación del portafolio de inversión, ello según su propio perfil y actitud respecto del riesgo.

Sin embargo, la regulación señala una opción "por defecto" en caso de que el cotizante no elija activamente el nivel de riesgo al que desea exponerse. Concretamente, la opción "por defecto" es que la inversión se dirige al fondo de riesgo moderado, a menos que el cotizante manifieste explícitamente su intención de invertir en alguno de los otros dos fondos. Empero, según la literatura económica y dados los diferentes horizontes de inversión, se supone que mientras los trabajadores que están cerca de la jubilación no deberían exponer sus ahorros a un alto nivel de riesgo, y por tanto deberían seleccionar un 
portafolio conservador, ${ }^{20}$ los trabajadores más jóvenes deberían optar siempre por el portafolio de inversión de más alto riesgo (Benartzi \& Thaler, 2001; Beshears, Choi, Laibson, \& Madrian, 2009; Malkiel, 2015).

No está claro por qué el regulador local decidió que la opción "por defecto" sea el portafolio de riesgo moderado incluso para los trabajadores más jóvenes; sin embargo, estos bien podrían corregir individualmente esto mediante una selección "activa" del fondo de alto riesgo. De hecho, las previsiones al momento de la creación de los multifondos señalaban que el portafolio de alto riesgo sería el que más ahorradores y aportes tendría dado que el 57\% de los trabajadores en Colombia son menores de 35 años (García \& Moreno, 2011). Sin embargo, cinco años después de la entrada en vigencia de los "multifondos", solo el 1\% de los recursos del sistema se encuentran en el portafolio de alto riesgo, y cerca del $85 \%$ de los afiliados continúan "por defecto" en el portafolio de riesgo moderado (Asofondos, 2015).

Más allá de si la opción "por defecto" en el caso de los multifondos es o no realmente la mejor decisión que podrían tomar los trabajadores más jóvenes si se les permitiera hacer una elección activa, lo cierto es que las evidencias infieren una actitud pasiva y generalizada en lo que a esta decisión se refiere, es decir, en realidad parece que poco importa el contenido sustancial de la opción "por defecto" predefinida por la regulación. Parece que las personas no están muy atentas a lo importante que puede ser tomar una decisión equivocada o no respecto de su situación financiera en la vejez; más allá de ello, lo que nos dice el sesgo de statu quo es que las personas sin importar su condición, si son jóvenes o no, si son más o menos educados, simplemente siguen predecible y sesgadadamente el "camino que ofrece menor resistencia" y que ofrece la opción "por defecto".

20 Según la regulación local, quienes están cerca a la edad de jubilación quedan inscritos obligatoriamente en el portafolio de riesgo conservador. 


\section{Una reflexión acerca de la ética y los nudges}

Una de las conclusiones implícitas del presente trabajo es que, por un lado, existe una tendencia de las personas a actuar anómalamente, por ejemplo, manteniendo el statu quo, una de cuyas manifestaciones es la tendencia a aceptar irreflexivamente las opciones "por defecto" sin importar el contenido sustancial de la opción. Por otro lado, tal contenido ( $v g r$. si se trata de un sistema opt-in o de un sistema opt-out respecto de un plan de ahorro para jubilación) depende exclusivamente de la decisión premeditada de un empleador o de un regulador acerca de lo que él mismo considera que debe ser la opción "por defecto", entonces, surge como evidente el trasfondo "ético y moral" que suscita la utilización de nudges por parte de las empresas, pero sobre todo, cuando se trata del gobierno, la regulación y de las políticas públicas diseñadas por este.

Sobre este particular, puede decirse que si un nudge es por definición una medida que altera premeditadamente la denominada "arquitectura de la decisión" a fin de "empujar" a las personas hacia una dirección que es ex ante predecible, pero sin proscribirles ni ordenarles ninguna opción en particular, entonces, puede afirmarse que, en general, los nudges pueden tomar innumerables formas, y de hecho, poseen una naturaleza omnipresente, y esto aun cuando las personas no sean del todo conscientes de su existencia. A eso es lo que nos referimos con que, aunque efectivamente las personas se vean a sí mismas como autónomas y defiendan normativamente la libertad y la no interferencia exógena en su toma de decisión individual, en múltiples contextos, los nudges las llevan a que tomen decisiones de manera "inconsciente". De ahí que no sea una cuestión menor preguntarse si en presencia de un nudge, las personas pueden considerarse "auténticamente" libres de decidir, o si por el contrario, estas medidas no son más que interferencias "astutas" y "mimetizadas" en la toma de decisión, que por tanto deben generar un mínimo de suspicacia ética y moral. ${ }^{21}$

\footnotetext{
21 Para una discusión sobre las cuestiones éticas y morales involucradas en el uso de opciones "por defecto" en específico, los nudges y el paternalismo suave en general, cfr. Bovens (2009);
} 
Sobre este particular, además de los dos ejemplos desarrollados en este trabajo, e incluso antes de que en la academia empezara a discutirse en torno al trasfondo "ético y moral" de la utilización de nudges, las empresas han venido haciendo uso de ellos (quizá con otra denominación) a fin de "empujar" a las personas para que inconscientemente tomen ciertas decisiones que no necesariamente son las más favorables para ellas mismas. Por ejemplo, se sabe que la mayoría de los supermercados tienden a diseñar cuidadosamente y a ubicar premeditadamente en las estanterías ciertos productos y ciertas marcas de forma tal que esta "arquitectura de la decisión" empuje a los compradores para que "inconscientemente" adquieran aquellos productos que mayores márgenes de ganancia le reporten al mismo supermercado. ${ }^{22}$ En el mismo sentido, también se sabe que de tiempo atrás, los programadores de software, páginas web y plataformas de redes sociales tienden a dejar "premarcadas" ciertas opciones relacionadas con aspectos como permitir el envío de publicidad al usuario e incluso, opciones sobre privacidad y manejo de información personal, de forma tal que, a menos que el mismo usuario tome una decisión activa (vgr. que desmarque la opción premarcada en el software), este acepta compartir su información personal y permite que esta sea utilizada por la empresa. ${ }^{23}$

En estos, como en otros casos, el problema ético y moral no es menor. Aun cuando las personas quieran verse a sí mismas como libres y autónomas en su toma de decisiones, y por tanto, que crean que la

Hausman \& Welch (2010); Hausman \& Welch (2010); Grüne-Yanoff (2012); Wright \& Ginsburg (2012); White (2013); Smith, Goldstein, \& Johnson (2013); Mills (2015) entre otros.

22 En la literatura sobre marketing existen estudios que evidencian y sugieren incluso cómo ubicar los productos en las estanterías, a fin de que la mirada del consumidor se dirija inconscientemente hacia ellos, esto con el fin de que el consumidor prefiera adquirir estos productos, y por esta vía se incrementen los beneficios netos del supermercado. Al respecto, véase por ejemplo, Wilkinson, Mason, \& Paksoy (1982) y Chandon, Hutchinson, \& Bradlow (2009).

23 La mayoría de navegadores de páginas web tienen activada "por defecto" la opción de que estas páginas puedan almacenar cookies, los cuales son pequeños bloques de información acerca de las actividades que determinado usuario realiza en la red. Aunque en los navegadores esta opción puede desactivarse por parte del usuario, la mayoría de estos simplemente no la modifican, luego, mantienen el statu quo. Sobre este particular, véase por ejemplo, Kesan \& Shah (2006). 
existencia de una opción por defecto ( $v g r$. una casilla premarcada en un formulario) no es más que una "sutil" e "inofensiva" sugerencia acerca de lo que debieran decidir, en realidad, y como se mostró en el trabajo, estos nudges pueden determinar sensiblemente las decisiones de las personas. De hecho, y dada la influencia que los reguladores ya han reconocido a las opciones "por defecto" en materia de privacidad en Internet, ${ }^{24}$ por ejemplo, la Directiva Europea 95/46 establece que los programadores de software no pueden establecer como opción "por defecto" que este puede almacenar ni utilizar la información demográfica y de hábitos de compras del usuario; por el contrario, la Directiva ordena que este almacenamiento y utilización de información personal solo es posible si está precedido de un consentimiento explícito, una decisión activa -no meramente pasiva- por parte del usuario, es decir, en nuestros términos, que no se permite que la opción "por defecto" -aun cuando se pueda modificar con un simple clicsea que el usuario autoriza a que su información personal pueda ser guardada y utilizada por la empresa, luego que solo se permite que el usuario deba marcar la opción (decisión activa) si es que acepta que la empresa haga este tratamiento con su información personal.

Sin embargo, vale decir que la discusión "ética y moral" acerca del uso de nudges, en general, o de las opciones "por defecto", en específico, no es omnipresente sino que es más bien una cuestión de grado. Así, existen casos en los que el actuar pasivo del individuo respecto de la opción "por defecto" no parece sugerir ninguna suspicacia respecto de quien preestablece dicha opción, por ejemplo, cuando Microsoft decide que la fuente por "defecto" en cada nuevo documento en su MSWord es Arial tamaño 12. Más allá, existen casos intermedios en los que tal discusión "ética y moral” parece tornarse más o menos relevante, como cuando un restaurante que desea maximizar sus beneficios decide que la opción "por defecto" es un menú rico en grasas y carbohidratos. Finalmente están los casos en los cuales la discusión luce inevitable; sobre esto último, uno de los casos para-

\footnotetext{
24 Una discusión sobre esta influencia de las opciones por defecto en lo que respecta al manejo de información personal en el contexto del software puede consultarse en Johnson, Bellman, \& Lohse (2002).
} 
digmáticos es cuando la regulación decide que, en ausencia de una manifestación explícita, una decisión activa por parte del individuo, la opción "por defecto" es que sus órganos, una vez fallezca, pueden o no ser extraídos para ser trasplantados. ${ }^{25}$

Por supuesto, esta discusión posee un sinnúmero de aristas relacionadas con cuestiones como (i) si el uso de nudges en general, o de establecer en la regulación opciones "por defecto" en específico, nos debe llevar a repensar el rol del Estado respecto de las decisiones individuales incluso cuando las consecuencias - negativas- de estas no afectan a nadie distinto al mismo individuo; (ii) cuestionar la potencial "manipulación oculta" que supone la utilización de nudges en el contexto del Derecho y de las políticas públicas; (iii) ser incluso más escépticos acerca de las "buenas intenciones" del Estado cuando este trata de influir en la decisión, mediante una opción "por defecto"; (iv) cuestionar el verdadero lugar que ocupa la autonomía individual respecto de la utilización de nudges por parte del gobierno o el regulador; y quizá incluso, (v) replantear la manera misma como desde la filosofía moral deberíamos (re)entender la autonomía y la libertad individual.

Sin perjuicio de estas cuestiones problemáticas, a las cuales la literatura les ha venido prestando creciente atención, en estas últimas líneas nos limitaremos a presentar subrepticiamente un marco de reflexión basado en las críticas y la consistencia teórica de las alternativas de intervención diferentes a la utilización de opciones "por

\footnotetext{
25 Sobre este particular, la mayoría de los ordenamientos suelen establecer una regla de presunción de consentimiento de las personas según la cual, en ausencia de declaración acerca de la posibilidad de disponer de sus órganos una vez fallecen, se presume "por defecto" en algunos países que hay una voluntad de donar, y en otros países, se presume como que hay voluntad de no donar. Simultáneamente, es común que se permita que las personas hagan explícita su decisión en vida acerca de ser o no donantes, y a través de ello, que modifiquen libremente la opción "por defecto" (Monroy, 2012). Consistente con el sesgo de statu quo, la evidencia demuestra que las personas suelen no modificar la opción "por defecto" establecida por ordenamiento, lo que trae como consecuencia que los países en donde dicha opción "por defecto" es que existe una voluntad de donar generan hasta incluso seis veces más donantes que aquellos que funcionan con la regla contraria (Johnson \& Goldstein, 2003; Abadie \& Gay, 2006) (Johnson \& Goldstein, 2003).
} 
defecto" (sesgo de statu quo) en específico, así como de los nudges y el "paternalismo suave" en general.

$\mathrm{Al}$ respecto, creemos que las alternativas de intervención -al menos las más relevantes- que se disputan con el "paternalismo suave" surgen desde las dos nociones antagónicas que en conjunto construyen el concepto mismo: el paternalismo "duro" por un lado y la filosofía liberal por el otro. ${ }^{26}$

Respecto de la primera alternativa, y como se señaló en su momento, en la mayoría de los casos el paternalismo "duro" resulta prima facie objetable en el sentido en que su aplicación requiere que la medida, para considerarse auténticamente paternalista, debe propender por el bienestar, la felicidad o la mejor satisfacción de los intereses y de los valores que le convienen al individuo que es coaccionado por la misma medida. ${ }^{27} \mathrm{El}$ problema que surge para lograr lo anterior es que se requiere que "otros" (vgr. el Estado) definan un objetivo de orden normativo-valorativo acerca de lo que estos consideran que el individuo debe hacer con su propia vida para, por ejemplo, ser una persona más feliz o con mayor bienestar. Una vez definido dicho objetivo, "los otros" deben coaccionar al individuo para que dirija su comportamiento hacia la consecución de aquel. Si se prescinde de dicha coacción, pero no obstante permanece el objetivo a satisfacer, estaríamos en el terreno del paternalismo suave, el cual es objetado por el "paternalismo duro" precisamente porque en ausencia de coacción existiría el riesgo de que el individuo persiguiese otro objetivo, es decir, que decida algo que vaya en contra de su propia felicidad o bienestar.

Aunque la discusión en torno al paternalismo es bastante más extensa y profunda de lo que estamos mostrando acá, es importante señalar que la mayor objeción al paternalismo duro se origina en el pensamiento utilitarista y liberal clásico, según el cual es éticamente inadmisible que "otros" definan un objetivo de orden normativo-valorativo al cual

26 cfr. sesión supra 1.2 .

27 Véase la definición de "paternalismo" de Dworkin (1990). 
debe apuntar necesariamente el individuo, por el contrario, lo que se argumenta es que no pueden ser "los otros", sino que es el mismo individuo, quien se erige como el mejor evaluador acerca de lo que significa su propio bienestar o felicidad (Mill, 1980) ${ }^{28}$.

Ahora, desde la perspectiva liberal clásica, algunas de las objeciones al paternalismo suave y a la utilización de nudges por parte del Estado se basan en que estos funcionan como "manipuladores ocultos" pues lo que pretende esta forma de paternalismo es que el individuo persiga un objetivo de orden normativo-valorativo que es propuesto "por otros", pero sin que el propio individuo sea consciente de ello. Por otro lado, también se objeta que el paternalismo suave sugiere que el comportamiento "anómalo" (vgr. sesgo de statu quo) no debería ser corregido por el Estado, por el contrario, parece que conviene más que se profundice dicha forma "sesgada" de pensar, pues con ello el Estado podría conseguir más fácilmente sus objetivos. Estas objeciones - entre otras- hacen que desde la perspectiva liberal clásica, el paternalismo suave sea considerado ética y moralmente más reprochable que el mismo paternalismo duro (Grüne-Yanoff, 2012; Smith, Goldstein, \& Johnson, 2013).

Aunque la posición liberal clásica y su objeción al paternalismo suave está mejor fundamentada e incluso parece generar mayor simpatía que la posición del paternalismo "duro", su receta sin embargo puede conducir a una contradicción consigo misma, una sin-salida que no tiene que ver con su fundamentación, sino con su aplicación. Esta contradicción ha sido evidenciada precisamente por los defensores del paternalismo suave y de las políticas basadas en "nudges".

En efecto, un liberal clásico se opondría al paternalismo duro argumentando que el Estado, por ejemplo, no puede decidir coercitiva-

\footnotetext{
28 Sobre este punto, una objeción no menos importante respecto del paternalismo (tanto "duro" como "suave") es que, dado que los intereses individuales pueden ser tan heterogéneos y simultáneamente todos moralmente admisibles, entonces es fácticamente imposible que incluso un "dictador benevolente" pudiera determinar el objetivo de orden normativovalorativo al que debiere dirigirse el individuo. Sobre esta objeción consultar White (2013).
} 
mente qué debe hacerse con los órganos de un individuo una vez este fallece, pero también - por razones éticas y morales- tendría que oponerse al paternalismo suave y a que la regulación estableciese alguna opción "por defecto", ya sea a través de un sistema opt-in choice, o un sistema opt-out choice. Incluso el liberal clásico se opondría a que se le preguntara directamente a las personas si desean ser donantes de órganos, pues sin importar cómo se formule la pregunta, esta funcionaría siempre como un "manipulador oculto" tipo nudge..$^{29}$ En pocas palabras, en este caso un liberal clásico defenderá la tesis de que "los otros" (vgr. el Estado) no pueden decidir "nada", y que debe permitirse que el individuo decida "todo". Contempladas así las cosas, la contradicción es evidente: si el Estado "no decide nada" acerca de qué hacer con los órganos, en realidad está decidiendo que no se puede disponer de ellos a menos que el individuo haya decidido "todo"; en últimas está proponiendo un sistema opt-in choice, es decir, al menos en este caso, el Estado está dando nudges incluso cuando no hace nada.

La estructura argumentativa del ejemplo anterior y la contradicción evidenciada a la que llega el pensamiento liberal en este caso, puede replicarse a otras cuestiones como las opciones "por defecto" en materia de ahorro para jubilación, o a la manera como un restaurante dispone los alimentos; piénsese por ejemplo, ¿cómo sería la carta de un restaurante de un liberal clásico si, según él, la carta no puede contener ninguna opción "por defecto", ni puede poner ningún plato en primer lugar porque quizá esta primera opción (por llamativa) tienda a actuar como un nudge?

Con todo, lo que estamos tratando de evidenciar subrepticiamente como marco inicial de reflexión, es que en muchos casos, cuando "otros" (vgr. el Estado) no hacen "nada" respecto de la decisión individual, y por tanto pretenden que el individuo decida "todo", incluso en ese caso se pueden estar dando nudges. En otras palabras, en realidad parece que no tiene sentido discutir si optar premeditadamente por una política paternalista suave y aplicar nudges resulta ser

29 cfr. sesión 3.1 .1 supra. 
una decisión ética y moralmente reprochable; la verdadera discusión es que aun cuando el Estado no decide "nada", puede estar dando nudges, entonces no darlos es a veces una opción inevitable, ${ }^{30}$ luego, ¿cuál es la manera correcta de hacer las cosas? Y por tanto, ¿cuáles son los nudges que deberían aplicarse y hacia qué dirección?

\section{Referencias bibliográficas}

Abadie, A., \& Gay, S. (Julio de 2006). The Impact of Presumed Consent Legislation on Cadaveric Organ Donation: A Cross-Country Study. Journal of Health Economics, 25(4), 599-620.

Amir, O., \& Lobel, O. (Diciembre de 2008). Stumble, Predict, Nudge: How Behavioral Economics Informs Law and Policy. Columbia Law Review, 108(8), 2098-2137.

Ariely, D. (Mayo de 2008). 3 Main Lessons of Psychology. Recuperado de http:/ / danariely.com/2008/05/05/3-main-lessons-of-psychology/ Asofondos. (2015). Boletin Informativo Dirección de Estudios Económicos. Asofondos. Bogotá: Asofondos.

Ayala, U., \& Acosta, O. (Abril de 2002). Políticas para promover una ampliación de la cobertura del sistema de pensiones en Colombia. CEPAL: Serie de Financiamiento del Desarrollo(118), 1-67.

Balz, J., Sunstein, C., \& Thaler, R. (Abril de 2013). Choice Architecture. En E. Shafir, The Behavioral Foundations of Public Policy (pp. 428-439). New Jersey: Princeton University Press.

Banco Interamericano de Desarrollo. (2015). Panorama de las Pensiones: América Latina y el Caribe. Washington: Banco Interamericano de Desarrollo. Banco Mundial. (2013). Capacidades financieras en Colombia: resultados de la encuesta nacional sobre comportamientos, actitudes y conocimientos financieros. Washington: Banco Mundial.

Becker, G. (Primavera de 2012). The Potentials and Limitations of Rational Choice Theory: an Interview with Gary Becker . Erasmus Journal for Philosophy and Economics, 5(1), 73-86.

\footnotetext{
30 Sobre una defensa contextualizada de la inevitabilidad del paternalismo suave y los nudges cfr. Thaler \& Sunstein (2003a, 2003b); Sunstein (2013); Balz, Sunstein, \& Thaler (2013). Para una crítica sobre el mismo punto $c f r$. Hargreaves (2013) y Zanitelli (2009).
} 
Benartzi, S., \& Thaler, R. (Marzo de 2001). Naive Diversification Strategies in Defined Contribution Saving Plans. The American Economic Review, 91(1), 79-98.

Beshears, J., Choi, J., Laibson, D., \& Madrian, B. (2009). The Importance of Default Options for Retirement Saving Outcomes: Evidence from the United States. En J. Brown, J. Liebman, \& D. Wise, Social Security Policy in a Changing Environment (pp. 167-195). Chicago: University of Chicago Press.

Bovens, L. (2009). The Ethics of Nudge. En T. Grüne-Yanoff, \& S. Ove Hansson, Preference Change (pp. 207-219). Dordrecht: Springer.

Calabresi, G., \& Melamed, D. (invierno de 2011). Reglas de propiedad, reglas de responsabilidad y reglas de inalienabilidad: Un vistazo a la catedral. En G. Calabresi, Un vistazo a la catedral (pp. 363-404). Lima: Palestra. Camerer, C., \& Loewenstein, G. (2004). Behavioral Economics: Past, Present, Future. En C. Camerer, G. Loewenstein, \& M. Rabin, Advances in Behavioral Economics (pp. 3-51). New York: Princeton University Press. Camerer, C., Issacharoff, S., Loewenstein, G., O'Donoghue, T., \& Rabin, M. (Enero de 2003). Regulation for Conservatives: Behavioral Economics and the Case for "AsymmetricPaternalism". University of Pennsylvania Law Review, 151(3), 1211-1254 .

Camerer, C., Loewenstein, G., \& Rabin, M. (2004). Advances in Behavioral Economics. New Jersey: Princeton University Press.

Chandon, P., Hutchinson, W., \& Bradlow, E. Y. (Noviembre de 2009). Does In-Store Marketing Work? Effects of the Number and Position of Shelf Facings on Brand Attention and Evaluation at the Point of Purchase. Journal of Marketing, 73(6), 1-17.

Choi, J., Laibson, D., Madrian, B., \& Metrick, A. (2002). Defined Contribution Pensions: Plan Rules, Participant Decisions, and the Path of Least Resistance. En J. Poterba, Tax Policy and the Economy (Vol. 16, págs. 67-113). Cambridge: MIT Press.

Choi, J., Laibson, D., Madrian, B., \& Metrick, A. (2004). For Better or for Worse Default Effects and 401(k) Savings Behavior. En D. Wise, Perspectives on the Economics of Aging (p. 81-121). Chicago: University of Chicago Press.

Collins, D., Morduch, J., Rutherford, S., \& Ruthven, O. (2009). Portfolios of the Poor: How the World's Poor Live on $\$ 2$ a Day. New Jersey: Princeton University Press. 
Conly, S. (2013). Against Autonomy: Justifying Coercive Paternalism. Cambridge, United Kingdom: Cambridge University Press.

Dawes, R. M., \& Thaler, R. (Verano de 1988). Anomalies: Cooperation. The Journal of Economic Perspectives, 2(3), 187-197.

Demenchonok, E. (Enero de 2009). The Universal Concept of Human Rights as a Regulative Principle: Freedom versus Paternalism. The American Journal of Economics and Sociology, 68(1), 273-302.

Departamento Administrativo Nacional de Estadística. (14 de Mayo de 2014). DANE. Recuperado de https://www.dane.gov.co/index.php/ estadisticas-por-tema/pobreza-y-condiciones-de-vida/encuestalongitudinal-de-proteccion-social-elps

Downs, J., Loewenstein, G., \& Wisdom, J. (Mayo de 2009). Strategies for Promoting Healthier Food Choices. The American Economic Review, 99(2), 159-164.

Dworkin, G. (1990). El paternalismo. En J. Betegón, \& J. De Paramo, Derecho y Moral: Ensayos analíticos (pp. 147-161). Barcelona: Ariel.

Frank, R. H. (2005). Microeconómia y Conducta (Primera en español ed.). (E. Rabasco, \& L. Toharia, Trads.). Madrid: McGraw-Hill.

Fudenberg, D. (Septiembre de 2006). Advancing Beyond "Advances in Behavioral Economics". Journal of Economic Literature, 44(3), 694-711. García, C., \& Moreno, J. (Julio-Diciembre de 2011). Optimización de portafolios de pensiones en Colombia: el esquema de multifondos, 20032010. Ecos de Economía(33), 140-183.

Grüne-Yanoff, T. (Enero de 2012). Old Wine in New Casks: Libertarian Paternalism Still Violates Liberal Principles. Social Choice and Welfare, 38(4), 635-645.

Gugerty, M. (Enero de 2007). You Can't Save Alone: Commitment in Rotating Savings and Credit Associations in Kenya. Economic Development and Cultural Change, 55(2), 251-282.

Hargreaves, S. (Mayo de 2013). What is the Meaning of Behavioural Economics? Cambridge Journal of Economics, 37, 985-1000.

Hausman, D., \& Welch, B. (Marzo de 2010). Debate: To Nudge or Not to Nudge. Journal of Political Philosophy, 18(1), 123-136.

Ho, T., Lim, N., \& Camerer, C. (Agosto de 2006). Modeling the Psychology of Consumer and Firm Behavior with Behavioral Economics. Journal of Marketing Research, 43(3), 307-331. 
Huh, Y., Vosgerau, J., \& Morewedge, C. (Octubre de 2014). Social Defaults: Observed Choices Become Choice Defaults. Journal of Consumer Research, 41(3), 746-760.

Instituto Colombiano de Bienestar Familiar. (2010). Encuesta Nacional de la Situaciòn Nutricional en Colombia (ENSIN) - Resumen Ejecutivo. Bogotá: Instituto Colombiano de Bienestar Familiar.

Johnson, E., \& Goldstein, D. (Noviembre de 2003). Do Defaults Save Lives? Science, 302(5649), 1338-1339.

Johnson, E., Bellman, S., \& Lohse, G. (Febrero de 2002). Defaults, Framing and Privacy: Why Opting In-Opting Out. Marketing Letters, 13(1), 5-15.

Jolls, C., Sunstein, C., \& Thaler, R. (Mayo de 1998). A Behavioral Approach to Law and Economics. Stanford Law Review, 50(5), 1471-1550.

Kahneman, D. (2011). Thinking, Fast and Slow. New York: Farrar, Straus and Giroux.

Kahneman, D., \& Tversky, A. (Marzo de 1979). Prospect Theory: An Analysis of Decision under Risk. Econometrica, 47(2), 263-292.

Kahneman, D., Knetsch, J. L., \& Thaler, R. H. (Diciembre de 1990). Experimental Tests of the Endowment Effect and the Coase Theorem. The Journal of Political Economy, 98(6), 1325-1348.

Kahneman, D., Knetsch, J. L., \& Thaler, R. H. (Invierno de 1991). Anomalies: The Endowment Effect, Loss Aversion, and Status Quo Bias. The Journal of Economic Perspectives, 5(1), 193-206.

Kesan, J., \& Shah, R. (Diciembre de 2006). Setting Software Defaults: Perspectives from Law, Computer Science and Behavioral Economics. Notre Dame Law Review, 82(2), 583-634.

Kooreman, P., \& Henriëtte, P. (Junio de 2010). What Does Behavioral Economics Mean for Policy? Challenges to Savings and Health Policies in the Netherlands. De Economist, 158(2), 101-122.

Korobkin, R. B. (Marzo de 1998). The Status Quo Bias and Contract Default Rules. Cornell Law Review, 83, 608-687.

Korobkin, R., \& Ulen, T. (2000). Law and Behavioral Science: Removing the Rationality Assumption from Law and Economics. California Law Review, 88(4), 1051-1144.

Loewenstein, G., \& Thaler, R. (Otoño de 1989). Anomalies: Intertemporal Choice. The Journal of Economic Perspectives, 3(4), 181-193.

López, H., \& Lasso, F. (2012). El mercado laboral y el problema pensional colombiano. Borradores de Economía(736), 1-71. 
Lora, E., \& Pagés, C. (Octubre de 2000). Hacia un envejecimiento responsable: Las reformas de los sistemas pensionales América Latina. Research Department Working paper series - Banco Interamericano de Desarrollo(433), 1-49.

Luoto, J., \& Carman, K. (2014). BehavioralEconomics Guidelines with Applications for Health Interventions. Inter-American Development Bank, Technical Note IDB-TN-665. Washington: Inter-American Development Bank.

Madrian, B., \& Shea, D. (Noviembre de 2001). The Power of Suggestion: Inertia in 401(k) Participation and Savings Behavior. The Quarterly Journal of Economics, 116(4), 1149-1187.

Malkiel, B. (2015). Random Walk Down Wall Street: The Time-Tested Strategy for Successful Investing. New York: Norton \& Company.

Mesa-Lago, C. (Diciembre de 2004). Evaluación de un cuarto de siglo de reformas estructurales de pensiones en América Latina. Revista CEPAL(84), 59-82.

Mill, J. S. (1980). Sobre la libertad. Buenos Aires: Hyspamerica.

Mills, C. (Septiembre de 2015). The Heteronomy of Choice Architecture. Review of Philosophy and Psychology, 6(3), 495-509.

Ministerio de la Protección Social. (2011). Observatorio de Seguridad Alimentaria y Nutricional de Colombia: Componentes y lineamientos para su implementación. Medellín: Universidad de Antioquia.

Ministerio de Salud y Protección Social. (2013). Documento Técnico de la Situación en Seguridad Alimentaria y Nutricional ( $S A N)$. Bogotá: Ministerio de Salud y Protección Social.

Ministerio de Salud y Protección Social. (2013). Perfil nacional de consumo de frutas y verduras. Bogotá: Ministerio de Salud y Protección Social.

Monroy, D. (2012). El razonamiento heurístico y algunas implicaciones en el análisis económico del derecho: El caso de las normas sobre donación de órganos. En F. Castillo, \& J. S. Reyes, Relaciones contemporaneas entre derecho y economía (pp. 365-424). Bogotá: Grupo Editorial Ibañez.

Monroy, D. (Mayo de 2012). La comercialización de cigarrillos en Colombia y el "problema del autocontrol": La restricción de venta al menudeo. Working Paper, 1-32.

Monroy, D. (2014). Behavioral Economics: Origenes, metodología y herramientas de trabajo. Revista Entramado, 10(2), 184-206. 
Monroy, D. (2015). ¡Las Preferencias Dependen Del Punto De Referencia! Un desafío al Análisis Económico -y coaseano-del Derecho. Working paper, 1-35.

Monroy, D. (2016). Regulación ambiental y efecto dotación: algunos retos y -una- solución. En VV.AA., Instrumentos económicos y financieros para la gestión ambiental (pp. 335-383). Bogota: Universidad Externado de Colombia.

Mullainathan, S., \& Thaler, R. (Sepiembre de 2000). Behavioral Economics. Working Paper MIT(00-27), 1-13.

Presidencia de la República. (2013). Plan Nacional de Seguridad Alimentaria y Nutricional. Bogotá: Presidencia de la República.

Raafat, R., Chater, N., \& Frith, C. (Octubre de 2009). Herding in humans. Trends in Cognitive Sciences, 13(10), 420-428.

Samuelson, W., \& Zeckhauser, R. (1988). Status Quo Bias in Decision Making. Journal of Risk and Uncertainty, 1(1), 7-59.

Smith, N. C., Goldstein, D., \& Johnson, E. (Otoño de 2013). Choice Without Awareness: Ethical and Policy Implications of Defaults. Journal of Public Policy \& Marketing, 32(2), 159-172.

Sunstein, C. (Otoño de 2011). Empirically Informed Regulation. The University of Chicago Law Review, 78(4), 1349-1429.

Sunstein, C. (2012). Why Nudge?: The Politics of Libertarian Paternalism. New Haven, EE.UU.: Yale University Press.

Sunstein, C. (Mayo de 2013). The Storrs Lectures: Behavioral Economics and Paternalism. Yale Law Journal, 1826-1899.

Sunstein, C., \& Thaler, R. (Mayo de 2003a). Libertarian Paternalism. The American Economic Review, 93(2), 175-179.

Sunstein, C., \& Thaler, R. (Otoño de 2003b). Libertarian Paternalism Is Not an Oxymoron. The University of Chicago Law Review, 70(4), 1159-1202.

Thaler, R. (Otoño de 1988). The Ultimatum Game. The Journal of Economic Perspectives, 2(4), 195-206.

Thaler, R. (Invierno de 1990). Anomalies: Saving, Fungibility, and Mental Accounts. The Journal of Economic Perspectives, 4(1), 193-205.

Thaler, R. H., \& Sunstein, C. R. (2009). Un pequeño empujón (Nudge). México D.F., México: Taurus.

Thapaa, J., \& Lyford, C. (2014). Behavioral Economics in the School Lunchroom: Can it Affect Food Supplier Decisions? A Systematic Review. International Food and Agribusiness Management Review, 17(A), 187-208. 
Tversky, A., \& Kahneman, D. (Noviembre de 1991). Loss Aversion in Riskless Choice: A Reference-Dependent Model. The Quarterly Journal of Economics, 106(4), 1039-1061.

Tversky, A., \& Thaler, R. (Primavera de 1990). Anomalies: Preference Reversals. The Journal of Economic Perspectives, 4(2), 201-211.

Wansink, B. (Julio de 1996). Can Package Size Accelerate Usage Volume? Journal of Marketing, 60(3), 1-14.

Wansink, B., \& Cheney, M. (Invierno de 2006). Leveraging FDA Health Claims. Journal of Consumer Affairs, 39(2), 386-398.

Wansink, B., \& Kim, J. (Septiembre-Octubre de 2005). Bad Popcorn in Big Buckets: Portion Size Can Influence Intake as Much as Taste. Journal of Nutrition Education and Behavior, 37(5), 242-245.

Wansink, B., Just, D., Payne, C., \& Klinger, M. (Octubre de 2012). Attractive names sustain increased vegetable intake in schools. Preventive Medicine, 55(4), 330-332.

White, M. (2013). The Manipulation of Choice: Ethics and Libertarian Paternalism. New York: Palgrave Macmillan.

Wilkinson, J. B., Mason, B., \& Paksoy, C. (Febrero de 1982). Assessing the Impact of Short-Term Supermarket Strategy Variables. Journal of Marketing Research, 19(1), 72-86.

World Bank. (2015). World Development Report 2015 - Mind society and behavior. UU.UU.: Washington.

Wright, J., \& Ginsburg, D. (2012). Behavioral Law and Economics: Its Origins, Fatal Flaws, and Implications for Liberty. Northwestern University Law Review, 106(3), 1033-1090 .

Zanitelli, L. (Febrero de 2009). Default Rules and the Inevitability of Paternalism. Working Paper, 1-18. 